CASE REPORT

\title{
Usefulness of central venous oxygen saturation monitoring during bidirectional Glenn shunt
}

\author{
Nami Kakuta', Shinji Kawahito', Naoji Mita', Noriko Kambe', Asuka Kasai', \\ Narutomo Wakamatsu', Toshiko Katayama', Tomohiro Soga', Fumihiko Tada², \\ Takashi Kitaichi $^{3}$, Tetsuya Kitagawa ${ }^{3}$, and Hiroshi Kitahata ${ }^{4}$ \\ ${ }^{1}$ Department of Anesthesiology, Tokushima University Hospital, Tokushima, Japan, ${ }^{2}$ Department of An- \\ esthesia, Shikoku Medical Center for Children and Adults, Kagawa, Japan, ${ }^{3}$ Department of Cardiovascu- \\ lar Surgery, Tokushima University Hospital, Tokushima, Japan, ${ }^{4}$ Department of Dental Anesthesiology, \\ Tokushima University Hospital, Tokushima, Japan
}

\begin{abstract}
A PediaSat ${ }^{\mathrm{TM}}$ oximetry catheter (PediaSat : Edwards Lifesciences Co., Ltd., Irvine, CA, U.S.A.), which facilitates continuous measurement of central venous oxygen saturation $\left(\mathrm{ScvO}_{2}\right)$, may be useful for surgery for pediatric congenital heart disease. We used PediaSat during a bidirectional Glenn shunt. The patient was a 13-month-old boy. Under a diagnosis of left single ventricle (pulmonary atresia, right ventricular hypoplasia, atrial septal defect) and residual left aortic arch/left superior vena cava, a modified right BlalockTaussig shunt was performed. Cyanosis deteriorated, so a bidirectional Glenn shunt was scheduled. After anesthesia induction, a 4.5 Fr double-lumen $(8 \mathrm{~cm})$ PediaSat was inserted through the right internal jugular vein for continuous $\mathrm{ScvO}_{2}$ monitoring. Furthermore, the probe of a near-infrared, mixed blood oxygen saturation-measuring monitor was attached to the forehead for continuous monitoring of the regional brain tissue mixed blood oxygen saturation (rSO $)_{2}$ (INVOS ${ }^{\mathrm{TM}}$ 5100C, Covidien ; Boulder, CO, U.S.A.). Blockage of the right pulmonary artery and right superior vena cava decreased the oxygen saturation, $\mathrm{ScvO}_{2}$, and $\mathrm{rSO}_{2}$, but increased the central venous pressure. Although changes in $\mathrm{ScvO}_{2}$ were parallel to those in $\mathrm{rSO}_{2}$, the former showed more marked changes. A combination of $\mathrm{ScvO}_{2}$ and $\mathrm{rSO}_{2}$ for monitoring during Glenn shunt may be safer. J. Med. Invest. 60 : 272 275, August, 2013
\end{abstract}

Keywords : bidirectional Glenn shunt, circulatory monitoring, central venous oxygen saturation, PediaSat oximetry catheter, near-infrared spectroscopy

\section{INTRODUCTION}

A PediaSat ${ }^{\mathrm{TM}}$ oximetry catheter (PediaSat: Edwards Lifesciences Co., Ltd., Irvine, CA, U.S.A.),

Received for publication May 13, 2013 ; accepted July 20, 2013.

Address correspondence and reprint requests to Nami Kakuta, M.D., Department of Anesthesiology, Tokushima University Hospital, 3-18-15, Kuramoto, Tokushima 770-8503, Japan and Fax : $+81-88-633-7182$. which facilitates continuous measurement of the central venous oxygen saturation $\left(\mathrm{ScvO}_{2}\right)$, may be useful for surgery for pediatric congenital heart disease, which induces marked changes in intraoperative circulatory kinetics $(1,2)$. We used PediaSat during a bidirectional Glenn shunt, and confirmed the usefulness of continuous $\mathrm{ScvO}_{2}$ measurement during surgery. 


\section{CASE REPORT}

The patient was a 13-month-old boy. His height and body weight were $74 \mathrm{~cm}$ and $10 \mathrm{~kg}$, respectively. Under a diagnosis of left single ventricle (pulmonary atresia, right ventricular hypoplasia, atrial septal defect) and residual left aortic arch/left superior vena cava, a modified right Blalock-Taussig (BT) shunt was performed 11 days after birth. Cyanosis deteriorated, and balloon dilatation was conducted to treat shunt anastomotic stenosis. However, there was no response. A bidirectional Glenn (hemi-Fontan) shunt was scheduled. Anesthesia was induced with midazolam, and muscle relaxation was achieved with rocuronium. Endotracheal intubation was performed using a tube measuring $4.5 \mathrm{~mm}$ in inner diameter (ID). Anesthesia was maintained with sevoflurane and fentanyl. After anesthesia induction, a 4.5 Fr double-lumen $(8 \mathrm{~cm})$ PediaSat was inserted through the right internal jugular vein for continuous $\mathrm{ScvO}_{2}$ monitoring. Furthermore, the probe of a near-infrared, mixed blood oxygen saturation-measuring monitor was attached to the forehead for continuous monitoring of the regional brain tissue mixed blood oxygen saturation $\left(\mathrm{rSO}_{2}\right)$ (INVOS $^{\mathrm{TM}} 5100 \mathrm{C}$, Covidien ; Boulder, CO, U.S.A.).
For transesophageal echocardiography, a multiplane for children (Philips, Inc. ; Andover, MA, U.S.A.) was used.

Cardiopulmonary bypass was not performed. Blockage of the right pulmonary artery and right superior vena cava decreased the oxygen saturation, $\mathrm{ScvO}_{2}$, and $\mathrm{rSO}_{2}$, but increased the central venous pressure (CVP). Immediately before blockage, $\mathrm{SpO}_{2}$, CVP, $\mathrm{rSO}_{2}$, and $\mathrm{ScvO}_{2}$ were $81 \%, 16 \mathrm{mmHg}, 66 \%$, and $83 \%$, respectively. However, after blockage, the values were $71 \%, 25 \mathrm{mmHg}, 50 \%$, and $50 \%$, respectively. Although the changes in $\mathrm{ScvO}_{2}$ paralleled those in $\mathrm{rSO}_{2}$, the former showed more marked changes. The response of $\mathrm{ScvO}_{2}$ was prompt, and there were no artifacts ; the value was stable. As both $\mathrm{rSO}_{2}$ and $\mathrm{ScvO}_{2}$ were maintained at $50 \%$, surgery was continued. After the blockage was relieved, all parameters promptly returned to the preblockage values. Changes upon blockage of the left pulmonary artery and left superior vena cava were slight. Subsequently, respiratory/circulatory kinetics stabilized, and surgery was completed (Figure). The postoperative course was favorable. The patient recovered well in the intensive care unit without any neurological issues.
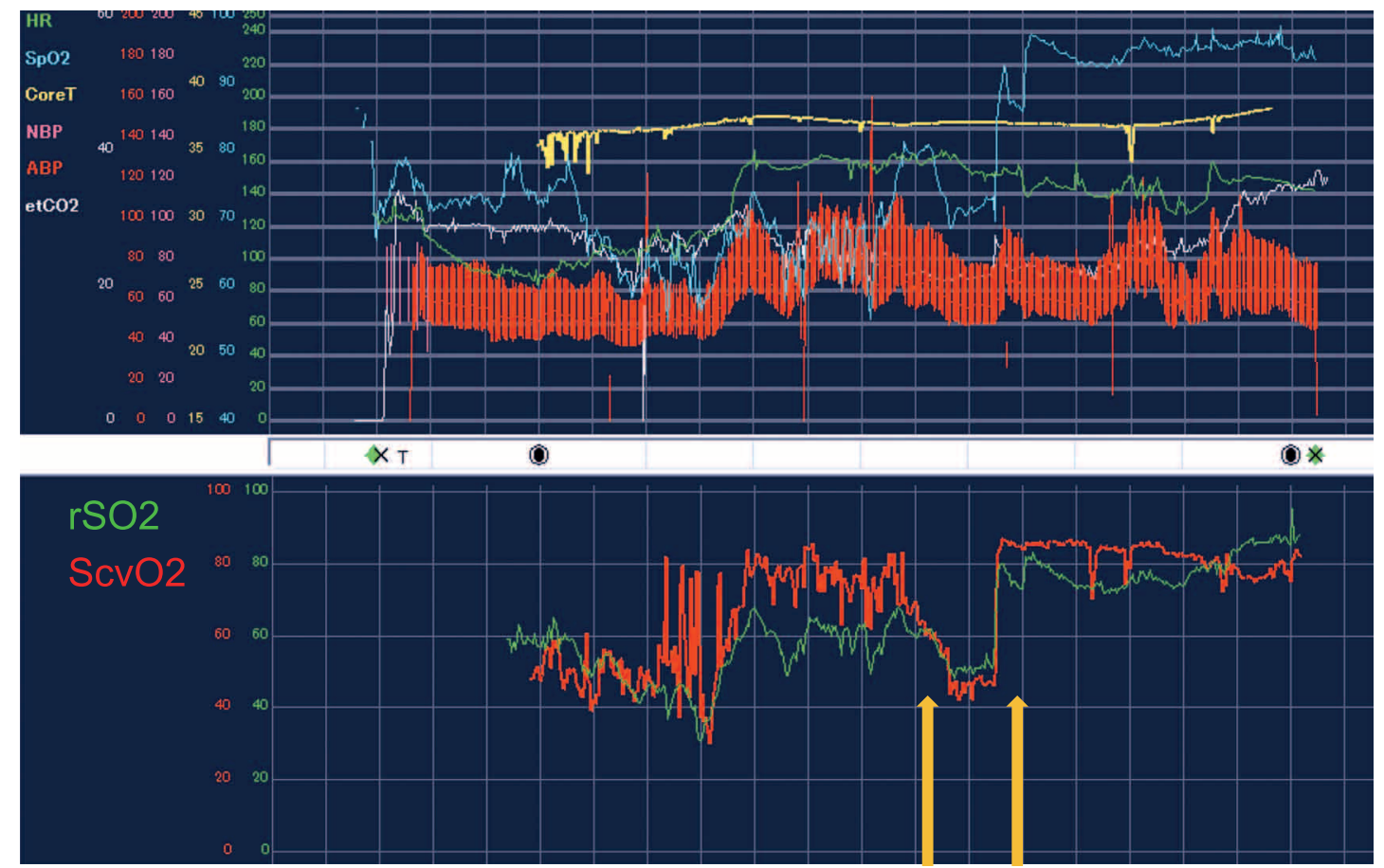

Figure : Anesthesia record

$\mathrm{HR}$ : Heart rate, $\mathrm{SpO}_{2}$ : Percutaneous oxygen saturation, CoreT : Core temperature, NBP : Noninvasive blood pressure, $\mathrm{ABP}$ : Arterial blood pressure, etCO 2 : End-tidal carbon dioxide, $\mathrm{rSO}_{2}$ : Continuous monitoring of the regional brain tissue mixed blood oxygen saturation, $\mathrm{ScvO}_{2}$ : Continuous measurement of the central venous oxygen saturation,

First arrow : Blockage of the right pulmonary artery and superior vena cava

Second arrow : Blockage of the left pulmonary artery and superior vena cava 


\section{DISCUSSION}

The bidirectional Glenn shunt is a commonly performed procedure in the treatment of univentricular physiology. It can be performed with or without cardiopulmonary bypass as long as pulmonary perfusion is maintained $(3,4)$. During the procedure, the superior vena cava (SVC) is clamped and the proximal pressure can rise as high as 40 to $55 \mathrm{mmHg}$. This can hamper cerebral perfusion. The duration of the procedure is variable, ranging from five to 30 minutes. During this period, reliable cerebral monitoring is essential.

The goal of continuous $\mathrm{ScvO}_{2}$ monitoring is to improve the conditions of severe-status patients by maintaining an appropriate balance between oxygen supply and consumption (5). The use of a PreSep ${ }^{\mathrm{TM}}$ CV Oximetry Catheter in adults and a PediaSat ${ }^{\mathrm{TM}}$ Oximetry Catheter in children facilitates continuous monitoring of the central venous oxygen saturation $\left(\mathrm{ScvO}_{2}\right) . \mathrm{ScvO}_{2}$ changes in parallel to mixed venous oxygen saturation $\left(\mathrm{S}_{\bar{v}}^{-} \mathrm{O}_{2}\right)$ (6). As $\mathrm{ScvO}_{2}$ depends on the cardiac output/hemoglobin level/arterial blood oxygen saturation involved in oxygen transport, as well as metabolism involved in oxygen consumption, continuous monitoring of the oxygen demand/supply balance is possible (7). A study performed a protocol involving goal-directed therapy (GDT) (8) to maintain $\mathrm{ScvO}_{2}$ at $70 \%$ or more in high-risk patients, and reported that a decrease in the mortality rate and reduction in the admission period were achieved (9). Systemic management using $\mathrm{ScvO}_{2}$ as an index was introduced to guidelines for septic shock treatment. Many studies have suggested the usefulness of $\mathrm{ScvO}_{2}(10,11)$. In children, the monitoring of changes in $\mathrm{ScvO}_{2}$ also facilitates prompt management, decreasing the incidence of complications and the mortality rate in those with congenital heart disease $(1,2)$.

As an index of cerebral perfusion, noninvasive monitoring of regional cerebral oxygen saturation by the use of near-infrared spectroscopy (NIRS) cerebral oximetry $\left(\operatorname{Invos}^{\mathrm{TM}}\right)$ has been used. The usefulness of $\mathrm{rSO}_{2}$ continuous monitoring during pediatric cardiac surgery has also been reported. It was reported that a close correlation was observed between cerebral NIRS and SVC oxygen saturation in neonates with congenital heart disease (12).

We performed the simultaneous monitoring of $\mathrm{ScvO}_{2}$ and $\mathrm{rSO}_{2}$ during a bidirectional Glenn shunt, during which blockage of the pulmonary artery/SVC may cause cerebral edema/ischemia, and confirmed the usefulness of the two parameters. In particular, the changes in $\mathrm{ScvO}_{2}$ were more marked than those in $\mathrm{rSO}_{2}$. The maximum frequency of $\mathrm{ScvO}_{2}$ renewal was once every two seconds. It was lower than that of $\mathrm{rSO}_{2}$ monitoring (6 times per second), but a sensitive response was achieved. Although $\mathrm{rSO}_{2}$, which is measured by attaching a probe to the forehead, also reflects information on venous blood to some extent, it facilitates brain-tissue monitoring, and is strongly influenced by the autoregulation capacity. As described above, the changes in $\mathrm{ScvO}_{2}$ were more marked than those in $\mathrm{rSO}_{2}$. This was possibly because the influence of the cerebral autoregulation capacity on $\mathrm{ScvO}_{2}$ was less marked than that on $\mathrm{rSO}_{2}$, since $\mathrm{ScvO}_{2}$ reflects the upper body venous blood oxygen saturation.

In this case, $\mathrm{ScvO}_{2}$ showed higher values during surgery than we expected (especially before blockage of the pulmonary artery and superior vena cava ; $\mathrm{ScvO}_{2} 83 \%$ ). During a hyperdynamic state of septic shock, so-called warm shock, $\mathrm{ScvO}_{2}$ is said possibly to show an abnormally high value by oxygen utilization disorder in the tissue or increase of shunts (11). However, a definitive conclusion cannot be drawn on this issue because we did not measure the real value of oxygen saturation in the superior vena cava by blood gas analysis; however, the patients might enter a hyperdynamic state by the effects of a high concentration of oxygen, general anesthesia, catecholamine, and so on. It is thought to be important to observe not the absolute value but the change over time of $\mathrm{ScrO}_{2}$. In addition, continuous measurement of $\mathrm{ScvO}_{2}$, in combination with other surrogates of organ perfusion ( $\mathrm{rSO}_{2}$, vital signs, lactate, etc.), can be used as a reliable monitor during bidirectional Glenn shunt.

\section{CONCLUSION}

We reported a patient in whom the usefulness of central venous oxygen saturation monitoring during bidirectional Glenn shunt was confirmed. Continuous $\mathrm{ScvO}_{2}$ monitoring with a PediaSat ${ }^{\mathrm{TM}}$ Oximetry Catheter may be particularly significant for performing cardiac surgery in children in whom there are marked changes in hemodynamics. This procedure may facilitate the prediction of a sign of hemodynamic disturbance that cannot be detected using other monitoring methods. As $\mathrm{ScvO}_{2}$ shows more marked changes than $\mathrm{rSO}_{2}$, a combination of these two parameters for monitoring during Glenn shunt 
may be safer. In particular, it may be very useful for bidirectional Glenn shunt in which cardiopulmonary bypass is not performed.

\section{CONFLICT OF INTEREST}

No conflicts of interest declared.

\section{REFERENCES}

1. Liakopoulos OJ, Ho JK, Yezbick A, Sanchez E, Naddell C, Buckberg GD, Crowley R, Mahajan $\mathrm{A}:$ An experimental and clinical evaluation of a novel central venous catheter with integrated oximetry for pediatric patients undergoning cardiac surgery. Anesth Analg 105 : 1598-1604, 2007

2. Spenceley N, Skippen P, Krahn G, Kissoon N : Continuous central venous saturation monitoring in pediatrics : a case report. Pediatr Crit Care Med 9 : e13-e16, 2008

3. Murthy KS, Coelho R, Naik SK, Punnoose A, Thomas W, Cherian KM : Novel techniques of bidirectional Glenn shunt without cardiopulmonary bypass. Ann Thorac Surg 67 : 17711774, 1999

4. Hussain ST, Bhan A, Sapra S, Juneja R, Das S, Sharma S : The bidirectional cavopulmonary (Glenn) shunt without cardiopulmonary bypass : is it a safe option? Interact Cardiovasc Thorac Surg $6: 77-82,2007$

5. Collaborative study group on perioperative $\mathrm{ScvO}_{2}$ monitoring : Multicentre study on periand postoperative central venous oxygen saturation in high-risk surgical patients. Crit Care
10 : R158, 2006

6. Reinhart K, Kuhn HJ, Hartog C, Bredle DL : Continuous central venous and pulmonary artery oxygen saturation monitoring in the critically ill. Intensive Care Med $30: 1572-1578$, 2004

7. Reinhart $\mathrm{K}, \mathrm{Bloos} \mathrm{F}$ : The value of venous oximetry. Curr Opin Crit Care $11: 259-263,2005$

8. Mayer J, Boldt J, Mengistu AM, Röhm KD, Suttner S : Goal-directed intraoperative therapy based on autocalibrated arterial pressure waveform analysis reduces hospital stay in high-risk surgical patients : a randomized, controlled trial. Crit Care 14 : R18, 2010

9. Rivers E, Nguyen B, Havstad S, Ressler J, Muzzin A, Knoblich B, Peterson E, Tomlanovich $\mathrm{M}$ : Early goal-directed therapy in the treatment of severe sepsis and septic shock. N Engl J Med 345 : 1368-1377, 2001

10. Perner A, Haase N, Wiis J, White JO, Delaney $A$ : Central venous oxygen saturation for the diagnosis of low cardiac output in septic shock patients. Acta Anaesthsiol Scand 54 : 98-102, 2010

11. Pope JV, Jones AE, Gaieski DF, Arnold RC, Trzeciak S, Shapiro NI, Emergency Medicine Shock Research Network (EMShockNet) Investigators : Multicenter study of central venous oxygen saturation $\left(\mathrm{ScvO}_{2}\right)$ as a predictor of mortality in patients with sepsis. Ann Emerg Med 55 : 40-46, 2010

12. Ricci Z, Garisto C, Favia I, Schioderer U, Giorni C, Fragasso T, Picardo S : Cerebral NIRS as a marker of superior vena cava oxygen saturation in neonates with congenital heart disease. Paediatr Anaesth 20 : 1040-1045, 2010 